\title{
ARTICLE
}

\section{Behavioral brittleness: the case for strategic behavioral public policy}

\author{
Ruth Schmidt* (D) and Katelyn Stenger (D) \\ Institute of Design, Illinois Institute of Technology, 3137 S. Federal Street, Chicago, IL 60616, USA and \\ Convergent Behavioral Science Initiative, University of Virginia, Olsson Hall 111B, Charlottesville, \\ VA 22904, USA \\ ${ }^{\star}$ Correspondence to: E-mail: schmidt@id.iit.edu
}

(Received 31 August 2020; revised 8 February 2021; accepted 24 March 2021)

\begin{abstract}
Despite widespread recognition that behavioral public policy (BPP) needs to move beyond nudging if the field is to achieve more significant impact, problem-solving approaches remain optimized to achieve tactical success and are evaluated by short-term metrics with the assumption of stable systems. As a result, current methodologies may contribute to the development of solutions that appear well formed but become 'brittle' in the face of more complex contexts if they fail to consider important contextual cues, broader system forces, and emergent conditions, which can take three distinct forms: contextual, systemic, and anticipatory brittleness. The Covid-19 pandemic and vaccination rollout present an opportunity to identify and correct interventional brittleness with a new methodological approach - strategic BPP (SBPP) - that can inform the creation of more resilient solutions by embracing more diverse forms of evidence and applied foresight, designing interventions within ecosystems, and iteratively developing solutions. To advance the case for adopting a SBPP and 'roughly right' modes of inquiry, we use the Covid-19 vaccination rollout to define a new methodological roadmap, while also acknowledging that taking a more strategic approach may challenge current BPP norms.
\end{abstract}

Keywords: behavioral design; public policy; strategy; complex systems; adaptation

\section{Introduction}

Thrust into the spotlight in the wake of the Covid-19 pandemic, behavioral public policy (BPP) interventions to reduce and contain the virus covered widespread territory, ranging from an initial focus on information dissemination, to norming effective handwashing, encouraging social distancing and mask-wearing, and promoting shelter-in-place recommendations (Bavel et al., 2020; Johnson et al., 2020; Lunn et al., 2020). As a field explicitly charged with applying evidence-based behavioral insights to inform effective public policy (Galizzi, 2014: Hansen, 2018), BPP was, arguably, perfectly positioned to deliver the goods. Yet, despite its clear urgency stricted re-use, distribution, and reproduction in any medium, provided the original work is properly cited. 
and applicability to the pandemic (Manning et al., 2020), BPP interventions have fallen somewhat short of expectations, and even individually effective interventions have struggled to contain the force of the coronavirus' spread to any substantive degree.

The extreme and varied conditions that shaped behavioral responses to the pandemic - prolonged and persistent uncertainty, waves of often contradictory approaches (Nelson \& Witko, 2020), and a high level of global variability that hampered generalizability (Iwuoha \& Aniche, 2020; Nicola et al., 2020) - reinforce that behavioral design cannot, and should not, be expected to manage such challenges on its own (Thaler, 2016). In the USA, for example, efforts to bolster public health recommendations about wearing masks were stymied by system-level supply issues, in addition to the entrenched effects of personal autonomy and political identity that fed reactance against nudges and appeals to social norms. More globally, even effective shelter-in-place mandates to reduce viral proliferation have also contributed to second-order effects such as struggles with behavioral health (Barari et al., 2020).

However, we suspect that some of the limitations, or 'brittleness,' exhibited by behavioral responses to Covid-19 may be the direct result of using methodology that is ill-suited to address challenges with this level of ongoing complexity. Traditional BPP methodology tends to focus on addressing bounded, present-tense and discretely measurable behavioral change, combining findings from empirical experiments with knowledge about the target environment to inform policy that achieves immediate relevance and results (Hallsworth et al., 2016; Cash et al., 2017; Irrational Labs, 2020). Optimizing for targeted solutions has emphasized the use of evidence-based problem-solving and randomized control trials (RCTs) to evaluate the efficacy of interventions; the same urge has more recently fed enthusiasm for advanced data analytics and its ability to heighten customization to increase the precision and efficacy of interventions (Kelders et al., 2012; Mills, 2020). In both cases, quantitative demonstration of scientific rigor has undeniably contributed to the field's achievements and perceived credibility (Sanders et al., 2018).

But the same attributes that contribute to BPP's success when creating policy interventions for 'last-mile' challenges have also positioned it as a largely tactical discipline that prioritizes accurately solving for narrow challenges over addressing underlying conditions or systemic root causes and short-term outcomes over greater resilience and long-term impact (Smith et al., 2009; Reijula et al., 2018; Ewert \& Loer, 2020). Not only does this emphasis on tactical problem-solving artificially constrain the nature of challenges the field might address, but it can reinforce tendencies to create solutions for individual issues within systems that may themselves be flawed or inequitable. It also puts current methodological approaches at odds with critiques from a growing number of behavioral practitioners who increasingly suggest that the field must find ways to tackle more complex and upstream challenges if it is to achieve its full promise and impact (Hansen, 2018; Spencer, 2018).

Resolving this tension puts the field at something of a crossroads. In one direction lies BPP's current trajectory of crafting finely tuned solutions for a narrow set of welldefined problems, and in the other applying current methodologies to more diverse challenges that puts them at increased potential risk for interventional brittleness. However, lessons learned from the mixed success of behavioral interventions to 
Covid-19 suggest that addressing interventional brittleness may not be an issue of simply applying traditional methodology better within complex or dynamic contexts and social systems (Holling, 2001; Tromp et al., 2011; Michie et al., 2013), but rather adopting an expanded set of methodological practices better suited to complexity.

This presents yet a third option: to define a more strategic model of problem-solving to combat the inherent brittleness that results from current problem-solving methodologies. Below, we outline the imperative for BPP practitioners and researchers to take this third path, both in the interest of applying these insights in complex contexts and as a means to expand BPP research and research partnerships. First, we discuss how current BPP methodological approaches contribute to contextual, systemic, and anticipatory forms of brittleness, which hinder the greater efficacy of behavioral change programs. Second, we articulate how taking a more proactive, strategic approach - strategic behavioral public policy (SBPP) expands on current methodology to imbue behavioral solutions with increased resilience to these forms of brittleness. Finally, we offer a road map for actionably applying SBPP, using the Covid-19 vaccine rollout as a sample case, and conclude with a discussion of potential considerations and path forward.

\section{Types of brittleness: contextual, systemic, and anticipatory}

BPP's preference for tightly framed problems, evidence-based interventions, and rigorous evaluative tools contribute significant benefits both to developing effective solutions and to communicating their credibility. Well-defined, discrete problems are an excellent fit for empirical inquiry. 'Gold standard' RCTs allow practitioners to more confidently quantify and attribute behavioral change to interventions, increasing BPP's methodological legitimacy to disciplines that sit outside the behavioral sciences (e.g., economics) in the form of translational boundary objects (Star \& Griesemer, 1989).

These norms are not in and of themselves bad or misguided. However, this steady diet of unambiguously defined problems and analytic methodology has, to some degree, made BPP a victim of its own success. The same precise and targeted interventions that provide confidence in 'fit' also contribute to the challenge of generalizability. While behavioral findings may be empirically sound, the experiments from which they are derived typically do not reflect real-world complexity and uncertainty: real-world conditions present heterogeneous and nondeterministic effects that can disrupt interventions' original intent if not supplemented by additional personal and cultural insight (IJzerman et al., 2020). The effects of solutions, once implemented, may be simultaneously boosted and dampened by other ancillary forces occurring within complex adaptive systems, characterized by nonlinear, multilevel behavior due to a lack of central control. Finally, even successful interventions may function within larger systems that are themselves inequitable and risk perpetuating or amplifying these inequities.

Collectively, this suggests that BPP's methodological attributes may inadvertently contribute to three forms of brittleness (see Table 1) in behavioral interventions: contextual brittleness, due to an insufficient grasp of the different perspectives and interpretations of proposed policy interventions; systemic brittleness, the failure to address 


\begin{tabular}{|c|c|c|c|}
\hline $\begin{array}{l}\text { Current behavioral design } \\
\text { methodological norms... }\end{array}$ & $\begin{array}{l}\text {...supply clear benefits of } \\
\text { precision and efficiency }\end{array}$ & $\begin{array}{c}\text { However, these norms may not } \\
\text { sufficiently recognize real-life } \\
\text { complexity... }\end{array}$ & $\begin{array}{c}\text {... which can lead to solutions } \\
\text { characterized by various forms of } \\
\text { 'brittleness' }\end{array}$ \\
\hline $\begin{array}{l}\text { Focusing on discrete behavior } \\
\text { change } \\
\text { Optimizing for specifics of user } \\
\text { context } \\
\text { Using empirical behavioral } \\
\text { insights demonstrated } \\
\text { through literature and } \\
\text { theory } \\
\text { Employing RCTs as a 'gold } \\
\text { standard' for evaluation }\end{array}$ & $\begin{array}{l}\text { Behavioral science literature and } \\
\text { RCTs are well suited to inform } \\
\text { tightly defined behavioral } \\
\text { challenges } \\
\text { Optimizing for specific settings or } \\
\text { situations increases the ability } \\
\text { to customize interventions } \\
\text { Behavior change can more readily } \\
\text { be attributed to interventions } \\
\text { RCTs provide quantifiable } \\
\text { evidence of intervention } \\
\text { success }\end{array}$ & $\begin{array}{l}\text { Heterogenous and } \\
\text { nondeterministic effects of } \\
\text { interventions may lead to } \\
\text { variable results (C) } \\
\text { Conditions for experimental } \\
\text { findings do not always align with } \\
\text { real-world complexity (C, S) } \\
\text { Interventions may function within } \\
\text { inherently inequitable systems } \\
\text { (C, S) } \\
\text { Even successful interventions may } \\
\text { result in unintended outcomes } \\
\text { (S, A) } \\
\text { RCTs do not project future efficacy } \\
\text { or capture emergent or evolving } \\
\text { conditions (S, A) } \\
\text { Second-order effects of } \\
\text { interventions may occur over } \\
\text { time (A) }\end{array}$ & $\begin{array}{l}\text { Contextual brittleness (C) } \\
\text { Interventions may not sufficiently account } \\
\text { for variable perception and uptake in } \\
\text { different populations } \\
\text { Systemic brittleness (S) } \\
\text { Insufficient insight into broader system } \\
\text { conditions and forces may } \\
\text { underestimate their effect on } \\
\text { interventions' effectiveness } \\
\text { Anticipatory brittleness (A) } \\
\text { Optimizing for stable, present-tense } \\
\text { conditions can result in solutions with } \\
\text { limited or short-term relevance when } \\
\text { conditions evolve }\end{array}$ \\
\hline
\end{tabular}

through literature and

ploying RCTs as a 'gold

to customize interventions

havior change can more readily

CTs provide quantifiable

evidence of intervention

success

However, these norms may not ly recognize real-life

erogenous and

variable results (C)

findings do not always align with

real-world complexity (C, S)

(C, S)

$(\mathrm{S}, \mathrm{A})$ olving

interventions may occur over 
how system forces both within and outside the intervention's sphere may impact their effectiveness; and anticipatory brittleness, which ignores how external conditions and end recipients of policy may themselves evolve.

\section{Contextual brittleness}

BPP methodology can result in contextually brittle solutions when interventions are insufficiently situated within the particulars of their context or are conceived with the assumption of 'normal' or universal values that ignore the pluralistic and heterogeneous nature of values, contexts, resources, or perceptions (Anderson, 1993; Soman \& Hossain, 2020). This can occur, for example, when insights from the behavioral literature are applied reductively to real-world user contexts (e.g., findings on increasing gym attendance are assumed to be a proxy for achieving good health) or when variable contexts lead individuals to embrace different behaviors or preferred outcomes due to cultural differences. As such, solving for contextual brittleness bears a family resemblance to solving for generalizability: where efforts to achieve generalizability typically focus on translating solutions that worked in one context [X] into another [Y], contextual brittleness occurs when a solution that is presumed to apply equally or generally across a single setting or situation [X] does not sufficiently take into account the multiplicity of perspectives that cause interventions to effectively splinter into a more diverse set of contexts $\left[\mathrm{X}_{1}, \mathrm{X}_{2}\right.$, and $\left.\mathrm{X}_{3}\right]$.

Several examples of contextual brittleness are evident, in the case of Covid-19, in incorrect assumptions of universal access to fresh water and soap required for handwashing (Iwuoha \& Aniche, 2020; World Health Organization, 2020) and in American Black men's concerns during the pandemic's early stages that wearing masks would result in tradeoffs between one form of safety (public health) and another (fears of racial profiling) (Alfonso, 2020; Vargas \& Sanchez, 2020; Yancy, 2020). In both cases, ostensibly benign or straightforward interventions were not actually neutral, and instead indicative that policy designers' assumptions of universal norms or shared values need to be interrogated during solution development (Djulbegovic \& Guyatt, 2017).

\section{Systemic brittleness}

A second form of vulnerability - systemic brittleness - can occur when solution development fails to consider critical system interactions, such as competing policies or trends, that cause interventions to function differently or in more limited ways than expected. For example, a nudge designed to encourage farmers to adopt watersaving practices in the water-scarce Colorado River Basin floundered when policy designers failed to consider the countereffects of competing policy interventions that incentivized 'use-it-or-lose-it' yearly water consumption rights (UCRC Staff \& Wilson Water Group, 2018). As a result, a behavioral change intervention to address water scarcity that seemed sound at the scale of individual farmers ultimately had the opposite effect.

Even behavioral interventions that are successful in isolation may miss the mark if they fail to consider how spillover or system effects compound or influence solutions, 
such as automatic payment nudges that inadvertently offset other forms of debt reduction (Dolan \& Galizzi, 2015; Adams et al., 2018). Alternately, adopting expressed consent interventions in organ donation contexts as a means to overcome the limitations of presumed consent may still fail to consider other critical system factors, such as evidence that the presence of donor coordinators boosts organ donation and successful transplant rates over rates achieved with behavioral change alone (Sarlo et al., 2016) or the uneven demand for particular organs (Wojda et al., 2017). In each case, systemic brittleness can be reduced when practitioners take into account how other infrastructural forces and activities may bolster, dampen, or redirect an intervention's intended effects.

It is worth noting that interventions can suffer simultaneously from multiple, compounding forms of brittleness. In the case of Covid-19, for example, entreaties to wear masks have struggled to overcome the perceived denial of personal liberties or conflation of mask-wearing with political beliefs (Sunstein, 2020a) - a manifestation of potential contextual brittleness - while conflicts between national-scale public health recommendations from the US Center for Disease Control (CDC) that contradicted local-scale directives coming from individual businesses or municipal officials (Nelson \& Witko, 2020) indicated the potential for systemic brittleness.

\section{Anticipatory brittleness}

Change is inevitable, but proactively designing for a third limitation - anticipatory brittleness - recognizes that interventions may weaken in the face of shifting or newly emergent contexts, and that certain trajectories, shifts, and cyclical events can be at least partially foreseen. Identifying regularly occurring cycles or upcoming events can help BPP practitioners consider emergent circumstances before they arise, such as when violations of social distancing and mask-wearing predictably increased with the emergence of warmer weather or when year-end holiday activities resulted in new peaks of infection. While many instances of anticipatory brittleness may arise from acute shifts in conditions, even well-established interventions like Save More for Tomorrow ${ }^{\mathrm{TM}}$ (Thaler \& Benartzi, 2004) may become increasingly brittle over time as the cohort of gig economy workers continues to grow and employer-run 401 ks become less the norm (Yildirmaz et al., 2020).

Anticipatory brittleness can also occur when policy interventions are installed without the recognition of unintended consequences or potential second-order implications of policy - as in perverse 'cobra effect' outcomes, in which policy interventions inadvertently spur behaviors contrary to their initial intent (Siebert, 2001) - or when individuals progressively adapt to interventions over time. In the case of Covid-19, anticipatory brittleness occurred when initial recommendations from international health organizations, including the US CDC and World Health Organization (WHO), asserted that laypeople without symptoms would not benefit from wearing masks in part to reserve N-95 masks for healthcare workers who urgently needed them; subsequent messaging fed by an evolving understanding of viral transmission that masks provided essential protection for everyone, regardless of disease status, led to hoarding, confusion, and skepticism that undercut its effectiveness (CDC, 2020; Missoni et al., 2020). 
While some effects of anticipatory brittleness may occur and resolve on a short timeframe, others are likely to have long-term consequences. The suggested mandate to work from home has already contributed to second-order effects on mental health (Barari et al., 2020), reported increases in domestic violence (Bradbury-Jones \& Isham, 2020), and real estate trends (Gujral et al., 2020; Tanrıvermiş, 2020), in addition to its obvious effect on daily household and professional activities. However, these shifts are already proving to have a disproportionately negative effect on women's employment and productivity, threatening to further exacerbate existing hiring, promotion, and income disparities in the longer term (Vincent-Lamarre et al., 2020). Similarly, findings that remote learning is disproportionally causing minoritized and underserved students to fall behind in school also suggest that public health responses to the pandemic may amplify existing inequities that range far beyond a single lost year of school (Alliance for Excellent Education, 2020; Hampton et al., 2020).

\section{Methodological implications to strategically addressing interventional brittleness}

Many have already recognized BPP's disciplinary limitations, calling attention to cultural and contextual factors in design and implementation (Levinson \& Peng, 2006; Banerjee et al., 2019; Soman \& Hossain, 2020), the need for a systems approach (Blizzard \& Klotz, 2012; Mažar, 2019; Ewert \& Loer, 2020), and solutions that adjust to users' emergent needs and behaviors (Broekhuizen et al., 2012; Riley et al., 2015). Even so, for the most part, these approaches still assume the use of traditional problem-solving methodologies and past data as evidence for future states (Howlett, 2020; Sunstein, 2020b), putting them at risk for falling back on old assumptions about what is worth measuring or prioritizing available data over what is most relevant.

While this may work as intended when navigating simpler contexts, more complex challenges and 'wicked problems' like the Covid-19 pandemic tend to resist analytic methodologies or adherence to past logic and trajectories (Rittel \& Webber, 1973; Buchanan, 1992). Navigating these more ambitious and ambiguous challenges may, therefore, require cultivating a greater appreciation for speculative and generative problem-solving modes (getting the right idea) as a co-equal complement to analytic and evaluative ones (getting the idea right) (Saltelli et al., 2020). Employing this more proactive, abductive approach complements BPP's familiar 'evidence of - proof of what works - with 'evidence for' - testimony for what could be - to generate hypotheses and solution components that integrate less obvious, but still plausible, scenarios into problem framing and policy intervention design (Biesta, 2007; Schmidt, 2020; Hermus et al., 2020). Addressing brittleness in these situations may, therefore, lie in an increased willingness to be strategically 'vaguely right rather than exactly wrong' (Read, 1920).

The notion of strategy is not altogether new to BPP discourse, and, in fact, a working definition of behavioral economics as 'psychology meets market forces' (Thaler, 2016) is highly aligned with a strategic mindset and operative context. Although 'strategy' has historically referred to helping policymakers make more strategic 


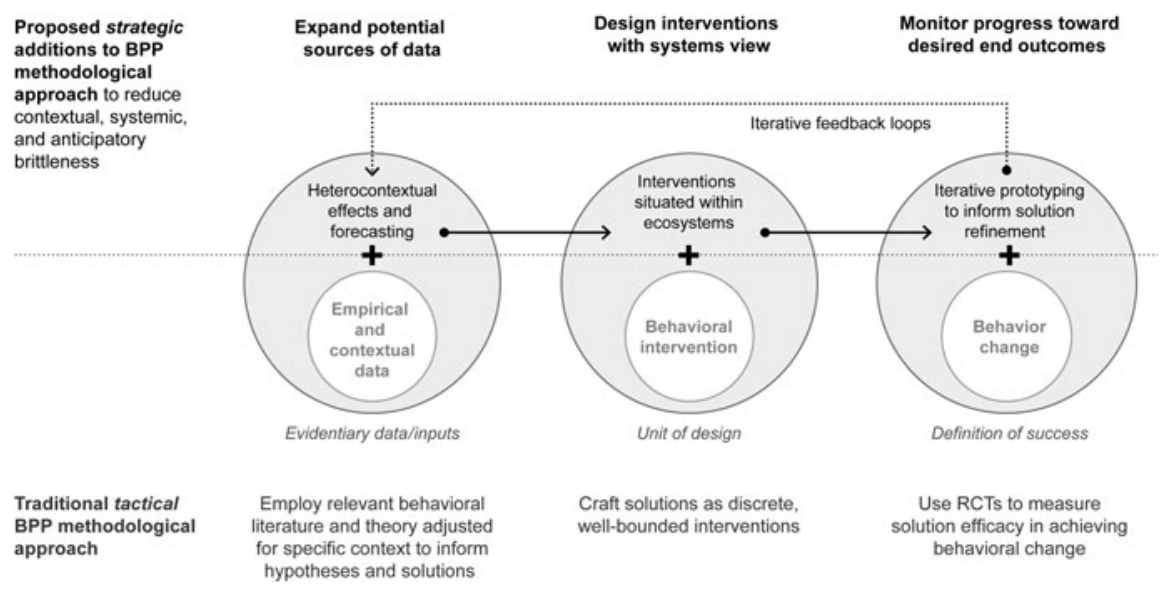

Figure 1. Strategic behavioral public policy methodology to combat brittleness.

decisions rather than encouraging the discipline itself to become more strategic (Bryson, 1988; Dudley \& Xie, 2020; George, 2020), public administrators have more recently adopted it to describe the creation of public value rather than domination over competitors (Bryson \& George, 2020). In practice, SBPP's underlying problem-solving path remains essentially the same as that of BPP, supplementing informational, evaluative, and analytic problem-solving methods with inspirational, generative, and synthetic approaches (Cross, 2006; Bjögvinsson et al., 2012; van Buuren et al., 2020). Applying a more strategic lens at each step, however, recenters behavioral challenges as part of a larger sequence of judgments and actions (rather than discrete instances), situated in system contexts with an eye toward eventual end outcomes (not in isolation), which are both active and acted upon (because interventions themselves impact the conditions into which they are placed) (Figure 1).

Where before hypotheses are informed primarily by behavioral science literature searches and the immediate context (IJzerman et al., 2020), they now benefit from additional evidence that reflects the heterogeneous and emergent nature of implementation and user contexts. An expanded strategic view also provides a new insight into supporting and countervailing system forces that may impact interventions once they are implemented, highlighting the need to consider the role of 'choice infrastructure' as well as choice architecture. Finally, where behavioral change has historically functioned as the primary indicator of success, its more longitudinal contributions to intended outcomes are also monitored to indicate the potential need for course correction.

\section{Expand potential sources of data}

Given that contextual brittleness arises from a mismatch between decontextualized evidence and the specificity and complexity of real-world settings, even replicated findings with high internal validity are unlikely to achieve equivalent levels of external validity (Levitt \& List, 2007; Camerer, 2011). Reducing potential brittleness in BPP, 
therefore, requires not only verifying the extent to which findings fit the context into which policy will be enacted (Diamond, 2010), but expanding the variety of data sources and use of mixed methods research, including qualitative, ethnographic, and phenomenological approaches, to supply a more well-rounded view of the relevant audience, challenge, and specific intervention context (Ewert \& Loer, 2020).

However, gathering more data may not address brittleness if they serve only to reinforce or fine-tune incoming hypotheses about what good looks like. Despite the long-standing credo that behavioral economics should be used to nudge 'for good' and in users' best interests (Thaler \& Sunstein, 2008; Sunstein, 2018), in practice, this stance often presumes notions of good as defined by behavioral designers and policymakers, rather than by policy recipients. When norms and values are embedded into assumptions of what to solve for - or what the problem even is practitioners can too easily overlook the potential for heterogeneous effects that put solutions at risk for contextual brittleness (Collins \& Evans, 2002).

In contrast, SBPP combats brittleness by taking a more pluralistic approach, eliciting a broader set of data about users and contexts to generate an understanding how heterogeneous populations may perceive or be unequally affected by interventions while hypotheses are still being formed (Grand, 2020). For example, historically unequal treatment and access to healthcare has contributed to US Black and Brown populations' skepticism of public health officials, suggesting that Covid-19 vaccination messages delivered by trusted community leaders may prove more persuasive (Poteat et al., 2020) than those delivered by medical professionals (Meng et al., 2016; Cotrau et al., 2019; Golemon, 2019; Laurent-Simpson \& Lo, 2019) or government officials (Wilkinson, 2013; Galizzi, 2014). Although addressing contextual brittleness remains distinct from achieving generalizability, gaining heterogeneous insight across user contexts through generative research methodologies can also contribute to the development of abstracted principles, or decision rules, that indicate how desirable characteristics of solutions might apply elsewhere without resorting to formula (Bohlen et al., 2020; Ho et al., 2020; Supplee \& Kane, 2020). The use of these principles as guardrails for hypothesis development, thus, functions less as prescriptive mandates for solution development and more to provide a shared set of attributes across many comparable challenges, while also recognizing the need to address specific contextual conditions when implementing concrete policy interventions.

A second potential expansion of data to inform hypotheses is the strategic use of foresight. Designing for future states is already well established in behavioral science in the form of 'planner-doer' tensions (Thaler \& Shefrin, 1981) or issues of control and volition (Nordgren et al., 2007; Sheeran \& Webb, 2016) such as when the stated desire to act sustainably contrasts with a lack of follow-through in the actual choicemaking context (Johnson, 2019; Falco \& Zaccagni, 2020). In addition, interest in superforecasters has indicated an openness to predictive data, albeit one primarily focused on improving individual judgment and decision-making ability rather than generating foresight into the systemic context into which interventions are to be applied (Mellers et al., 2015). But as the pandemic has ably demonstrated, changing conditions that require solving for new challenges or that render interventions less effective - such as evidence showing that the anticipated near-term availability of a vaccine decreases social-distancing measures (Andersson et al., 2020) - demand 
more substantive future-facing methodology situated in replicable and scalable methods, rather than in individual expertise.

The use of sensing and strategic scenario planning to take a more longitudinal view on the implications of plausible future states or policy directions (Schoemaker, 1995; Amer et al., 2013), frequently used in strategic business decisionmaking, is less common in BPP. Still, its ability to contribute useful perspectives to inform behavioral strategy shows strong promise: for example, a series of pre-Covid-19 pandemic simulations conducted with senior international government officials raised now-familiar concerns, including the need to impose restrictions on travel, supply and demand issues, and challenges caused by conflicting state and federal directives (Maxmen \& Tollefson, 2020). While scenario planning is not infallible - the exercise also failed to anticipate the degree to which an uncoordinated federal response would hinder efforts to curtail the spread of the virus - scenario-based forecasting can combat brittleness by providing data on likely condition shifts, system effects, and user adaptation that might impact intervention success while solutions are still being developed, deployed, and refined.

\section{Design interventions with systems view}

The value of a systems view is common to many classic definitions of strategy, ranging from achieving impact within market environments and ecosystems (Ansoff, 1979; Mintzberg, 1979; Henderson, 1989); references to patterns of actions and objectives (Learned et al., 1969; Mintzberg \& McHugh, 1985); and a sense of striving for unified, comprehensive, and integrated plans that recognize, or even emphasize, the interconnections between multiple parts (Glueck, 1976; Uyterhoeven et al., 1977). In a public policy context, complexity theory has afforded rich descriptions of public organizations as complex adaptive systems, indicating a need for adaptive stances among public policy practitioners when conceiving strategic approaches (Boulton et al., 2015), designing for dynamic public values (Haynes, 2018), and developing public policy practices that focus on system resilience, patterns of practice, and adaptability. In parallel, complex system science methodologies have been widely applied by policy practitioners when designing programs for complexity (Hassmiller Lich et al., 2017) and understanding critical policy issues such as climate change and mental health (Berry et al., 2018), indicating an opportunity for increased BPP applications.

Still, traditional approaches to BPP targeting behavioral change have tended to place less emphasis on the ways in which interventions influence and are influenced by other components of a system or at multiple scales, or defining requirements for methodologies that deal with structural design and implementation within systems (Jilke et al., 2019; Ewert et al., 2020; Ewert \& Loer, 2020). The lack of common behavioral models for analyzing external system forces analogous to those used in business strategy (e.g., PEST/PESTEL, STEEP, DPSIR, Lewin Force Field, etc.) suggests that designing for complex systems continues to present both a challenge and an opportunity for BPP (Sanders et al., 2018; Spencer, 2018), calling for a reconsideration of how to address policy system, institution, and implementation contexts with new tools, methods, and capabilities (Crowley et al., 2020). 


\section{Monitor progress toward desired end outcomes}

Popular behavioral design wisdom tends to encourage solving for the narrowest unit of analysis, encouraging tactical focus on behavioral change and positioning problem framing at the level of outcomes as a common failure mode (Irrational Labs, 2020). Taken too far, however, ignoring how policy interventions feed end outcomes can inadvertently introduce brittleness by insufficiently considering how they function within a larger ecosystem unit level, and the extent to which individual policies contribute to larger strategic goals.

This focus on behavioral change as a unit of success also has implications on testing and goals for achieving efficacy. While well-known behavioral problem-solving processes such as Define-Diagnose-Design-Test (Datta \& Mullainathan, 2014) and Test, Learn, Adapt (Haynes et al., 2012) suggest the use of low-cost, ethical RCTs as a means to measure and learn from the impact of policy interventions, BPP approaches still typically treat iteration as an opportunity to tinker with solutions in the interest of achieving more effective results for the problem that was initially identified, rather than to adapt them to adjust to new or emergent circumstances. Recentering evaluation as a feedback mechanism to support continual improvement resituates BPP interventions from tactical ends in themselves into strategic inputs that contribute to system-level change, helping policy designers more nimbly modify solutions in accordance with state shifts, knowledge of imminent trends, or observed user behaviors (Swanson \& Bhadwal, 2009) as well as providing fodder to address future challenges (Supplee \& Kane, 2020).

\section{A road map for applying SBPP}

Where above we described a general conceptual model for how SBPP might expand on traditional BPP practice, in the following section, we articulate how SBPP can reduce potential interventional brittleness in the context of a specific Covid-19 pandemic behavioral challenge: the vaccination rollout.

Efficiently and equitably distributing the vaccine to inoculate a global population remains both a logistical and a behavioral challenge (National Academies of Sciences, Engineering, and Medicine, 2020), where the latter issue clearly shares key similarities to efforts to encourage flu shots through messaging and scheduling nudges (Chen \& Stevens, 2017; Bruine de Bruin et al., 2019). However, other attributes of the Covid-19 vaccination plan indicate that it may be particularly susceptible to contextual, systemic, and anticipatory brittleness. Diverse populations, perceptions, and fears related to the vaccine - ranging from broader antivax views to concerns about side effects, the desire for more proof of efficacy, and skepticism that vaccines developed to combat the original strain will be effective on newly emergent strains - increase the chances that one-size-fits-all interventions will suffer from contextual brittleness. Decentralized and opaque staging and sign-up processes are already compounded by erratic supply and the need to navigate multiple levels of contradictory federal, state, and community guidelines, putting behavioral solutions at immediate risk for systemic brittleness. Finally, unlike the one-and-done flu vaccine, Covid-19's twodose protocol increases chances of anticipatory brittleness due to a high likelihood of complacency and reduced vigilance maintaining other preventive behaviors such 


\begin{tabular}{|c|c|c|c|c|}
\hline & \multicolumn{2}{|c|}{ Expand potential sources of data and evidence } & \multirow{2}{*}{$\begin{array}{l}\begin{array}{c}\text { Design interventions with } \\
\text { systems view }\end{array} \\
\begin{array}{l}\text { Situating interventions } \\
\text { within ecosystems }\end{array}\end{array}$} & \multirow{2}{*}{$\begin{array}{l}\begin{array}{c}\text { Monitor progress toward desired } \\
\text { end outcomes }\end{array} \\
\begin{array}{l}\text { Employing iterative prototyping } \\
\text { to inform solution refinement }\end{array}\end{array}$} \\
\hline & $\begin{array}{l}\text { Designing for heterocontextual } \\
\text { effects }\end{array}$ & $\begin{array}{l}\text { Applying foresight to explore } \\
\text { future scenarios }\end{array}$ & & \\
\hline \multirow{2}{*}{$\begin{array}{l}\text { Relevant } \\
\text { methods and } \\
\text { techniques }\end{array}$} & Generative user research & \multirow[t]{2}{*}{ Behavioral planning } & Choice infrastructure & Early-stage prototyping \\
\hline & Participatory design & & Solution resiliency & Feedback loops \\
\hline \multirow[t]{2}{*}{$\begin{array}{l}\text { Contributions to } \\
\text { combat } \\
\text { brittleness }\end{array}$} & \multirow[t]{2}{*}{$\begin{array}{l}\text { Multifaceted user perspectives } \\
\text { and perceptions (e.g., } \\
\text { historical or social context, } \\
\text { barriers to access) combat } \\
\text { contextual brittleness by } \\
\text { heightened awareness of } \\
\text { 'average user' limitations and } \\
\text { increased solution legitimacy }\end{array}$} & \multirow[t]{2}{*}{$\begin{array}{l}\text { Knowledge of likely emergent } \\
\text { or cyclical shifts, potential } \\
\text { user adaptations, and } \\
\text { unintended consequences } \\
\text { address anticipatory } \\
\text { brittleness by suggesting } \\
\text { how interventions might } \\
\text { need to evolve or adapt }\end{array}$} & $\begin{array}{l}\text { Early identification of }+/- \text { or } \\
\text { upstream system forces } \\
\text { and leverage points } \\
\text { that might impact } \\
\text { intervention } \\
\text { effectiveness addresses } \\
\text { systemic brittleness }\end{array}$ & \multirow[t]{2}{*}{$\begin{array}{l}\text { Integration of leading and } \\
\text { lagging metrics through } \\
\text { feedback loops provides early } \\
\text { warning signals for emergent } \\
\text { issues or anomalies, } \\
\text { indicating opportunities to } \\
\text { reduce brittleness at earlier } \\
\text { stages of development or } \\
\text { during implementation }\end{array}$} \\
\hline & & & $\begin{array}{l}\text { Ability to leverage existing } \\
\text { infrastructures builds } \\
\text { redundancy and } \\
\text { structural reinforcement } \\
\text { (e.g., lag time) into } \\
\text { interventions to increase } \\
\text { design resilience }\end{array}$ & \\
\hline
\end{tabular}

combat historical or social context, iers to access) combat heightened awareness of 'average user' limitations and ncreased solution legitimacy 
as social distancing after one dose (Andersson et al., 2020) and failures of followthrough to receive the recommended second dose. Further anticipatory brittleness is likely to result from concerns about vaccine effectiveness for viral mutations, as well as predictable misperceptions of cause-and-effect when vaccines given to already-infected individuals are falsely blamed for patient morbidity or mortality. Collectively, this suggests that augmenting traditional BPP tactics with methods that address these forms of potential brittleness (Table 2) can support a more strategic policy approach to Covid-19 vaccination uptake.

\section{Designing for heterocontextual effects: generative user research and participatory design}

While nudges and traditional behavioral approaches used to increase flu shots provide a helpful starting point, a successful coronavirus vaccine rollout must also consider the variable interpretations of messaging across communities and cultures, as well as issues of access and message legitimacy. Two additional methods - generative user research and participatory design - may prove beneficial as means to broaden BPP practitioners' understanding of both end users and their contexts.

As described above, the use of qualitative data in BPP is not new (Van Bavel \& Dessart, 2018; Ewert \& Loer, 2020), but the addition of more generative 'design thinking' qualitative methods as a means to elicit more specific knowledge about disparate user contexts, conditions, and perceptions has only more recently begun to gain traction (Kimbell, 2016). In contrast to qualitative research such as focus groups to evaluate hypotheses that have already been constructed, generative user research in SBPP is instead conducted at early stages of a project to ensure that problem frames and hypotheses are informed by real-life user needs, (mis)perceptions, and limitations as a means to expand, rather than confirm, practitioners' understanding of the problem to be solved, or even what qualifies as a problem in need of addressing (Schmidt, 2020). Its purpose is not to provide statistically significant data on what works, but to ensure that problem definition and solution development are not reduced to solving for generic or average users, and are instead informed by insight into user constraints, identity, kinship, or even age (Utych \& Fowler, 2020); in other words, where evaluative research can gauge the comparative effectiveness of different message frames, generative research can indicate when, and for whom, messaging tactics are even appropriate. Generative research on Covid-19 vaccination plans that reveals essential service workers hesitate to get vaccinations due to worries about missing work, or at-risk seniors struggle to navigate complex sign-up systems, for example, might suggest that multiple significant practical issues of access must be addressed if messaging nudges to encourage vaccinations are to be maximally useful.

A second means to more strategically reduce contextual brittleness lies in expanding who is included in intervention design, through participatory design. Participatory design activities stem from the notion that involving people as full participants, rather than test subjects, into the framing and design of solutions will result in more strategic, equitable, and contextually appropriate solutions, which improves the perceived relevance and credibility of policy interventions (Bjögvinsson et al., 2012; Blomkamp, 2018). When successful, employing participatory design can reduce 
contextual brittleness by incorporating bottom-up heterogeneous values and perspectives into the framing and conceptualization of interventions at the outset of design. This resituates policymakers from top-down experts who design for - or worse still, design 'at' - end users to facilitators who design with them, with the goal of engaging hard-to-reach populations, fostering cooperation and trust between different groups, and informing more contextually valid, transparent, and legitimate solutions (Blomkamp, 2018; Trischler et al., 2018) and working relationships (Bowen et al., 2013).

While participatory methodologies remain somewhat underutilized in BPP critical discourse and practice, an openness to embracing new forms of participant involvement in the development of interventions is evident in new proposals for 'selfnudging' (Reijula \& Hertwig, 2020), which further decenter the role of policy designers by placing ownership of decision-making and design firmly in the hands of users (Benjamin et al., 2020). Applied to a broader set of challenges, an increased application of participatory methods may also help address BPP's tendency to favor nudges or interventions that focus on individual behavior approaches, and which risk ignoring the potential benefits of collective activity when solving large-scale problems. In the case of the vaccine rollout, for example, participatory design sessions that include clinicians and administrative staff in addition to vaccine recipients would bring to light where perceptual and operational barriers across groups align and conflict, increasing the chances that solutions will solve for healthcare professionals as well as end users.

\section{Applying foresight to explore future scenarios: behavioral planning}

Given the myriad shifts and evolving narrative of the Covid-19 saga, policy-driven interventions to address the vaccine rollout are highly likely to suffer from anticipatory brittleness. Borrowing from strategic design and futures thinking, a behavioral planning approach draws on knowledge of context and potential shifts to consider likely adaptations, confluent effects, and new and emergent conditions in order to surface three common assumptions or 'errors of projection': stability (that interventions function within inherently stable systems), persistence (that system conditions remain the same over time), and value (that definitions of success are universally shared across contexts) (Schmidt \& Stenger, 2021). Anticipating soon-to-be events or slowly emergent but plausible near-future conditions can help practitioners mitigate the risks of BPP solutions by allowing practitioners to more systematically identify relevant systems forces and emergent future conditions that may contribute to interventional brittleness before solutions are fully designed or implemented (Jones et al., 2017).

By playing out the consequences of likely emergent events and the potential impact of policies on other system components and on one another, practitioners can develop more robust design considerations that inform 'roughly right' directional hypotheses and solutions at earlier stages of policy development. For example, exploring the proposed Covid-19 vaccine protocol through a behavioral planning lens surfaces several potential complexities and barriers to desired behaviors: while a two-dose protocol provides far greater immunity than a single shot, it also requires 
users to navigate additional decision-making and action points. This may require developing policies that augment targeted messaging or social norms to boost receptivity and plans to get vaccinated (Lewandowsky et al., 2021) with interventions to address issues of motivation and access to return for the second dose, such as supplementing messaging with immunization camps or incentives to increase followthrough (Bates \& Glennerster, 2017). Behavioral planning can also help practitioners play out other common scenarios, such as the potential behavioral implications from living in a mixed household where individuals may receive the vaccine at different times, or ways in which news or anecdotal stories about vaccine side effects may raise or perpetuate hesitation to seek vaccination.

Embracing foresight does not mean adopting automagical interventions based on groundless predictions (Riley et al., 2015) or predicting away the genuine uncertainty of viral mutations. Rather, the applied use of foresight suggests staying attuned to emergent issues and evolving views - such as increased clarity on the pros and cons of single shot, delayed booster, or double-dose Covid-19 vaccination protocols to design policy with an eye toward plausible future conditions, rather than only for the present tense or what is already known.

\section{Situating interventions within ecosystems: choice infrastructure and increasing solution resilience}

The Covid-19 vaccine rollout is unquestionably a complex 'system of systems' challenge that lies at the intersection of public health, economics, governmental policy, and logistics, putting policy interventions at high risk for systemic brittleness. Despite its surface similarity to flu vaccination programs, a fully conceived solution may, therefore, manifest more as system transformation than as a discrete solution (Dorst, 2019), requiring a systems approach that considers existing infrastructures and systems of exchange to reduce the chances that interventions fail due to operational conflicts and limitations, inequitable execution, or inconsistent enforcement (Shore et al., 2012; Bothwell et al., 2016; Supplee \& Kane, 2020).

This requires designing for systems-level 'choice infrastructure' as well as user-level choice architecture, using analogous or adjacent systems first as inspiration to identify relevant underlying operational mechanisms and user mental models, and secondly, to explore how these might be leveraged or built upon. For example, policymakers tackling the coronavirus vaccine rollout can borrow from structural and behavioral parallels with flu vaccine logistics or interactions to make use of current infrastructures (e.g., where to receive injections; norms of health plan coverage) and build user confidence, while also recognizing where differences (e.g., the need for cold storage; navigating a new sign-up process) require fundamentally new processes and conditions to support desirable behaviors. Additional systems design methods to identify systems of exchange and flows of tangible and intangible assets, such as asset mapping, can help practitioners develop relevant policy components, incentives, and narratives at micro (e.g., individual), meso (e.g., community and municipal), and macro (e.g., health system) scales (Nogueira et al., 2019), building on the presence of potential 'leverage points,' or ostensibly small changes within complex systems have outsize influence on downstream behaviors and flows (Meadows, 1999). 
Finally, situating BPP interventions within ecosystems requires becoming sensitive toward the multiple, nondeterministic outcomes of interventions themselves. Integrating redundancies - a hallmark of resilience in complex systems - into BPP solutions can act as a fail-safe in cases where individual interventions fail to deliver expected results or need course correction (Howlett, 2019). For example, despite research demonstrating the benefits of using prosocial messages to increase desirable behaviors in response to the pandemic, other sources indicate a need for more engagement than text messages (Favero \& Pedersen, 2020). This suggests that a complex systems scenario such as the vaccine rollout is even more likely to benefit from multiple reinforcing forms of policy to increase solution resilience, employing existing infrastructural mechanisms or partnerships to support both defensive strategies (e.g., protecting against negative consequences, such as reducing barriers to vaccine access for those at the highest risk) and offensive ones (e.g., introducing persuasive disincentives, such as requiring proof of vaccination to travel).

\section{Evaluating progress toward desired end outcomes: early-stage prototyping and feedback loops}

In contrast to flu vaccination interventions, the coronavirus vaccine rollout is already proving to be arduous, erratic, and lengthy: in other words, a perfect storm of potential contextual, systemic, and anticipatory brittleness. This makes it an ideal candidate for iterative evaluation methodologies that capture directional progress and indicators for course correction, such as prototyping and feedback loops.

While RCTs still have a clear role to play in evaluating intervention efficacy, the use of low-fidelity early-stage prototypes can elicit useful feedback before solutions are even complete, helping practitioners identify what needs adjustment when effort and cost - is still relatively low (Camburn et al., 2017; Schmidt \& Stenger, 2021). The ability to iterate in the interest of systems-level outcomes may be even more critically important in quickly evolving instances like Covid-19, where second- and third-order implications of interventions occur on an unusually short wavelength and adopting good behaviors like mask-wearing and handwashing have been shown to result in risk compensation (Mantzari et al., 2020) and substitution effects (Adams et al., 2018; Yan et al., 2020). Although the use of prototyping as an evaluative mechanism in BPP has become increasingly common (Hermus et al, 2020), its application as a generative device to test directional or exploratory thinking when formulating public policies or design public services is still fairly nascent (Mintrom \& Luetjens, 2016; Kimbell \& Bailey, 2017; Bason, 2019; van Buuren et al., 2020). However, this notion of prototyping concepts, rather than solutions, can also provide significant benefit to the development of more SBPP; just as participatory design embeds broader perspectives into solution development, prototyping early thinking to inform problem definition can better ensure that eventual policy interventions are solving for the right things.

Achieving increased solution resiliency also implies having time to respond as contexts change and adaptation sets in (Nair \& Howlett, 2016). Where RCTs provide evidence-based proof of efficacy and prototyping can enrich solution development processes, a third form of evaluation - feedback loops - can supply ongoing insight into policy effectiveness through the use of lagging and leading metrics. Traditional 
BPP metrics of success tend to be lagging; while helpful in gauging uptake or behavioral change, they typically provide a backward-looking view to indicate the extent to which policy interventions have worked. In contrast, leading metrics signal more emergent conditions and 'weak signals' (Ansoff, 1975), providing an early warning system about the state of system conditions and user behaviors that widens the window of opportunity between initial indications of system breakdowns and their full emergence, and allowing those responsible for the system to act earlier on the delay (Meadows, 1999).

Leading metrics in environmental policy environments have long been emphasized by the European Environment Agency, which posits that deep uncertainties at the time of policy creation can be reduced if policymaking is adaptive and sensitive to relevant changes (European Environment Agency, 2001). Leading metrics can also provide critically important insight into contexts where important indicators require noting the absence of events, infections, and fatalities that do not occur. In the vaccine rollout context, for example, leading metrics indicating low utilization of digital tools to schedule vaccination appointments might signal the need to address flaws in the sign-up program far in advance of capturing lagging metrics in the form of a low percentage of administered doses. Finally, attention to leading metrics can also help surface anomalies or 'Black Swan' events and emergent trends that would otherwise be ignored or dismissed, identifying potential opportunities for course correction or strategic adaptation at earlier stages of development and implementation (Kaplan et al., 2020).

\section{Potential considerations and a path forward}

Although this article primarily uses Covid-19 as a means to define, illustrate, and address the phenomenon of brittleness in BPP methodology, this should not be perceived as either a boundary on areas at risk for brittleness or the limited applicability of SBPP. On the contrary, interventional brittleness that would benefit from strategic methodology can be found in many other BPP settings presenting a high degree of systems complexity, such as sustainability or other public health challenges. Regardless of the area of application, however, adopting a SBPP approach will require overcoming two strong but interrelated tendencies at the heart of current methodological traditions: the propensity to seek precision in problem definition as a means to achieve rigor, but at the potential expense of broader effectiveness, and a predisposition to see behavioral challenges predominantly as the domain of analytical problem-solving, rather than eliciting expertise of a wider range of disciplines.

The limitations of behavioral science methodologies and nudging are well recognized, even by its advocates (Thaler, 2017; Reijula et al., 2018), but - in the parlance of business strategy - perceived constraints on BPP's 'where to play' (i.e., which problems to address) and 'how to win' (i.e., how to solve them) may also be somewhat self-imposed (Lafley \& Martin, 2013). BPP's proven track record tackling last-mile challenges has contributed to a steady diet of more of the same; over time, this has led to a kind of tautological standoff, where the nature of problems that BPP is tasked with solving are those that current methodology happens to solve well, but which has also inadvertently contributed to typecasting BPP as a discipline fit to address only certain types of problems. 
If anything, however, Covid-19 and other large-scale public health and sustainability challenges indicate that insights used to inform BPP interventions are as applicable to complex conditions as they are well-defined and predictable ones, but also that policymakers must develop new appetites for methodologies that embrace, rather than excise, uncertainty (Sanders et al., 2018; Spencer, 2018), and for qualitative data that provide directional, rather than confirmatory, evidence in order to address them. While this may feel at odds with traditional BPP notions of evidence-based rigor, it is not inconsistent with more sociological and sociotechnical views on human behavior that take a more expansive view of the social contexts and constructs in which people interact (Bruch \& Feinberg, 2017; Ewert \& Loer, 2020).

Solving for this tension may, therefore, be closely tied to developing an increased appetite for interdisciplinarity, with SBPP or 'advanced' versions of the discipline (Ewert \& Loer, 2020) expanding on, rather than replacing, current notions of how to solve challenges and who gets to solve them. Despite plentiful research suggesting that diverse groups outperform homogenous groups (Hong \& Page, 2004; Phillips, 2014), BPP has tended to maintain largely insular ownership over behavioral policy problem-solving methodologies. Even when BPP has looked beyond its own discipline, invitations to collaborate have primarily been extended only to other social sciences or analytically driven disciplines like data analytics as partners (Feitsma \& Whitehead, 2019). This indicates that, somewhat ironically, practitioners who are steeped in an awareness of cognitive biases may still suffer from disciplinary partisanship and limited epistemological networks (Brister, 2016) that prevent them from seeing the value of further adjacent disciplines.

Given the value of systems thinking and foresight in tackling complex BPP challenges, becoming more strategic may also require turning to disciplines that are inherently more comfortable and effective in navigating complexity and ambiguity (Buchanan, 1992). The fields of 'design thinking' or human-centered design already contribute lightly to behavioral problem-solving through insight into end-user contexts and notions of empathy, but their potential to contribute more substantive input into hypothesis and solution development in a policy context has yet to be fully conceptualized and developed (Schmidt, 2020). Encouragingly, 'design science' has more recently become recognized within public policy and public administration as worthy of study and application (Shangraw \& Crow, 1998; Barzelay, 2019; George, 2020; Hermus et al., 2020). Still, making BPP problem-solving more strategic may require recentering hypothesis development and problem-solving from a singular and top-down activity owned by behavioral policymakers to a more broadly collaborative one.

\section{Conclusion}

In this article, we suggest that employing traditional BPP methodology to address system challenges is likely to introduce three forms of brittleness - contextual, systemic, and anticipatory - into solutions. To correct for these forms of brittleness and achieve greater solution resilience, we propose a methodology for SBPP that expands on current methodological approaches. We then use the Covid-19 vaccination rollout to detail a methodological road map describing how BPP practitioners 
might develop more strategic solutions in practice and conclude by indicating potential limitations and the necessity of expanding beyond a tight disciplinary mindset if this approach is to be adopted.

Embracing a shift to SBPP may initially seem daunting, even far-fetched. But the Covid-19 pandemic not only supplies plentiful examples of brittle policy interventions; it also highlights BPP's willingness to adapt disciplinary assumptions. The field's collective desire to combat the pandemic has galvanized the efforts and expertise of the international BPP community, prioritizing collaboration, easier access to information, and speculative early results in the form of preprints over the usual norms of peer review (Final Mile, 2020; Matias \& Leavitt, 2020; Tidwell, 2020). In such an urgent context, the field's recognition that it is worthwhile to trade by-the-book precision for 'roughly right' processes provides some hope that the similarly nontraditional path of BPP to address contextual, systemic, and anticipatory brittleness can be seen in an analogous light.

Acknowledgements. We thank the editors and anonymous reviewers for their comments and guidance that substantially improved this article.

\section{References}

Adams, P., B. Guttman-Kenney, L. Hayes, S. Hunt, D. Laibson and N. Stewart (2018), The semblance of success in nudging consumers to pay down credit card debt (Occasional Paper No. 45). Financial Conduct Authority. Retrieved from: https://www.fca.org.uk/publication/occasional-papers/occasionalpaper-45.pdf.

Alfonso, F. III (2020), Why some people of color say they won't wear homemade masks. Retrieved from: https://www.cnn.com/2020/04/07/us/face-masks-ethnicity-coronavirus-cdc-trnd/index.html.

Alliance for Excellent Education (2020), Students of color caught in the homework gap. Alliance for Excellent Education. Retrieved from: https://futureready.org/wp-content/uploads/2020/08/HomeworkGap_FINAL8.06. 2020.pdf.

Amer, M., T. U. Daim and A. Jetter (2013), 'A review of scenario planning', Futures, 46: 23-40. https://doi. org/10.1016/j.futures.2012.10.003.

Anderson, E. (1993), Value in ethics and economics. Havard University Press. Retrieved from: https://nissenbaum.tech.cornell.edu/papers/Anderson.pdf.

Andersson, O., P. Campos-Mercade, A. N. Meier and E. Wengstrom (2020), Anticipation of COVID-19 vaccines reduces social distancing. Retrieved from: http://www.armandomeier.com/wp-content/uploads/ 2020/12/vaccine_socialdistancing.pdf.

Ansoff, H. I. (1975), 'Managing strategic surprise by response to weak signals', California Management Review, 18(2): 21-33. https://doi.org/10.2307/41164635.

Ansoff, H. I. (1979), Strategic management. London: Macmillian.

Banerjee, P., P. Chatterjee, S. Mishra and A. A. Mishra (2019), 'Loss is a loss, why categorize it? Mental accounting across cultures', Journal of Consumer Behaviour, 18(2): 77-88. https://doi.org/10.1002/cb. 1748.

Barari, S., S. Caria, A. Davola, P. Falco, T. Fetzer, S. Fiorin, L. Hensel, A. Ivchenko, J. Jachimowicz, G. King, G. Kraft-Todd, A. Ledda, M. MacLennan, L. Mutoi, C. Pagani, E. Reutskaja and F. R. Slepoi (2020), 'Evaluating COVID-19 Public health messaging in Italy: Self-reported compliance and growing mental health concerns', MedRxiv, 2020.03.27.20042820. https://doi.org/10.1101/2020.03.27.20042820.

Barzelay, M. (2019), Public management as a design-oriented professional discipline, Northhampton, MA: Edward Elgar Pub.

Bason, C. (2019), Design for policy (1st ed.). Burlington, VT: Routledge.

Bates, M. A. and R. Glennerster (2017), The Generalizability Puzzle (SSIR). Stanford Social Innovation Review. Retrieved from: https://ssir.org/articles/entry/the_generalizability_puzzle. 
Bavel, J. J. V., K. Baicker, P. S. Boggio, V. Capraro, A. Cichocka, M. Cikara, M. J. Crockett, A. J. Crum, K. M. Douglas, J. N. Druckman, J. Drury, O. Dube, N. Ellemers, E. J. Finkel, J. H. Fowler, M. Gelfand, S. Han, S. A. Haslam, J. Jetten and R. Willer (2020), 'Using social and behavioural science to support COVID-19 pandemic response', Nature Human Behaviour, 1-12. https://doi.org/10.1038/ s41562-020-0884-z.

Benjamin, D., K. Cooper, O. Heffetz and M. Kimball (2020), 'Self-reported wellbeing indicators are a valuable complement to traditional economic indicators but are not yet ready to compete with them', Behavioural Public Policy, 4(2): 198-209. https://doi.org/10.1017/bpp.2019.43.

Berry, H. L., T. D. Waite, K. B. G. Dear, A. G. Capon and V. Murray (2018), 'The case for systems thinking about climate change and mental health', Nature Climate Change, 8(4): 282-90. https://doi.org/10.1038/ s41558-018-0102-4.

Biesta, G. (2007), 'Why "What Works" won't work: Evidence-based practice and the democratic deficit in educational research', Educational Theory, 57(1): 1-22. https://oi.org/10.1111/j.1741-5446.2006.00241.x.

Bjögvinsson, E., P. Ehn and P.-A. Hillgren (2012), 'Design things and design thinking: Contemporary participatory design challenges’, Design Issues, 28(3): 101-16. https://doi.org/10.1162/DESI_a_00165.

Blizzard, J. L. and L. E. Klotz (2012), 'A framework for sustainable whole systems design', Design Studies, 33 (5): 456-79. https://doi.org/10.1016/j.destud.2012.03.001.

Blomkamp, E. (2018), 'The promise of co-design for public policy', Australian Journal of Public Administration, 77(4): 729-43. https://doi.org/10.1111/1467-8500.12310.

Bohlen, L. C., S. Michie, M. de Bruin, A. J. Rothman, M. P. Kelly, H. N. K. Groarke, R. N. Carey, J. Hale and M. Johnston (2020), 'Do combinations of behavior change techniques that occur frequently in interventions reflect underlying theory?', Annals of Behavioral Medicine, 54(11): 827-42. https://doi.org/10.1093/ abm/kaaa078.

Bothwell, L. E., J. A. Greene, S. H. Podolsky and D. S. Jones (2016), 'Assessing the gold standard-Lessons from the history of RCTs', New England Journal of Medicine, 374(22): 2175-81. https://doi.org/10.1056/ NEJMms1604593.

Boulton, J. G., P. M. Allen and C. Bowman (2015), Embracing complexity: Strategic perspectives for an age of turbulence, Oxford: Oxford University Press.

Bowen, S., K. McSeveny, E. Lockley, D. Wolstenholme, M. Cobb and A. Dearden (2013), 'How was it for you? Experiences of participatory design in the UK health service', CoDesign, 9(4): 230-46. https://doi. org/10.1080/15710882.2013.846384.

Bradbury-Jones, C. and L. Isham (2020), 'The pandemic paradox: The consequences of COVID-19 on domestic violence', Journal of Clinical Nursing, https://doi.org/10.1111/jocn.15296.

Brister, E (2016), 'Disciplinary capture and epistemological obstacles to interdisciplinary re-search: Lessons from central African conservation disputes', Studies in History and Philosophy of Biological and Biomedical Sciences, 56: 82-91.

Broekhuizen, K., W. Kroeze, M. N. M. van Poppel, A. Oenema and J. Brug (2012), 'A systematic review of randomized controlled trials on the effectiveness of computer-tailored physical activity and dietary behavior promotion programs: An update', Annals of Behavioral Medicine: A Publication of the Society of Behavioral Medicine, 44(2): 259-86. https://doi.org/10.1007/s12160-012-9384-3.

Bruch, E. and F. Feinberg (2017), 'Decision-making processes in social contexts', Annual Review of Sociology, 43(1): 207-27. https://doi.org/10.1146/annurev-soc-060116-053622.

Bruine de Bruin, W., A. M. Parker, M. Galesic and R. Vardavas (2019), 'Reports of social circles' and own vaccination behavior: A national longitudinal survey', Health Psychology, 38(11): 975-83. https://doi.org/ 10.1037/hea0000771.

Bryson, J. M. (1988), 'A strategic planning process for public and non-profit organizations', Long Range Planning, 21(1): 73-81. https://doi.org/10.1016/0024-6301(88)90061-1.

Bryson, J. M. and B. George (2020), Strategic management in public administration. Oxford Research Encyclopedia of Politics. https://doi.org/10.1093/acrefore/9780190228637.013.1396.

Buchanan, R. (1992), 'Wicked problems in design thinking', Design Issues, 8(2): 5-21. https://doi.org/10. $2307 / 1511637$.

Camburn, B., V. Viswanathan, J. Linsey, D. Anderson, D. Jensen, R. Crawford, K. Otto and K. Wood (2017), 'Design prototyping methods: State of the art in strategies, techniques, and guidelines', Design Science, 3, https://doi.org/10.1017/dsj.2017.10. 
Camerer, C. (2011), The Promise and Success of Lab-Field Generalizability in Experimental Economics: A Critical Reply to Levitt and List (SSRN Scholarly Paper ID 1977749; SSRN). Social Science Research Network. https://doi.org/10.2139/ssrn.1977749.

Cash, P. J., C. G. Hartlev and C. B. Durazo (2017), 'Behavioural design: A process for integrating behaviour change and design', Design Studies, 48: 96-128. https://doi.org/10.1016/j.destud.2016.10.001.

CDC (2020), Considerations for wearing masks. Centers for Disease Control and Prevention. Retrieved from: https://www.cdc.gov/coronavirus/2019-ncov/prevent-getting-sick/cloth-face-cover-guidance.html.

Chen, F. and R. Stevens (2017), 'Applying lessons from behavioral economics to increase flu vaccination rates', Health Promotion International, 32(6): 1067-73. https://doi.org/10.1093/heapro/daw031.

Collins, H. M. and R. Evans (2002), 'The third wave of science studies: studies of expertise and experience', Social Studies of Science, 32(2): 235-96. https://doi.org/10.1177/0306312702032002003.

Cotrau, P., V. Hodosan, A. Vladu, C. Daina, L. G. Daina and C. Pantis (2019), 'Ethical, socio-cultural and religious issues in organ donation', Moedica, 14(1): 12-4. https://doi.org/10.26574/maedica.2019.14.1.12.

Cross, N. (2006), Designerly ways of knowing (2006 ed.), London: Springer.

Crowley, K., J. Stewart, A. Kay and B. W. Head (2020), Reconsidering policy: Complexity, governance and the state. Chicago: Policy Press.

Datta, S. and S. Mullainathan (2014), 'Behavioral design: A new approach to development policy', Review of Income and Wealth, 60(1): 7-35. https://doi.org/10.1111/roiw.12093.

Diamond, P. (2010), 'Unemployment, vacancies and wages.' Speech, Sveriges Riksbank Prize in Economic Science in Memory of Alfred Nobel, December 8. Retrieved from: http://economics.mit.edu/files/6574.

Djulbegovic, B. and G. H. Guyatt (2017), 'Progress in evidence-based medicine: A quarter century on', Lancet, 390(10092): 415-23. https://doi.org/10.1016/S0140-6736(16)31592-6.

Dolan, P. and M. M. Galizzi (2015), 'Like ripples on a pond: Behavioral spillovers and their implications for research and policy', Journal of Economic Psychology, 47: 1-16. https://doi.org/10.1016/j.joep.2014.12.003.

Dorst, K. (2019), 'Design beyond design', She Ji: The Journal of Design, Economics, and Innovation, 5(2): 117-27. https://doi.org/10.1016/j.sheji.2019.05.001.

Dudley, S. E. and Z. Xie (2020), 'Nudging the nudger: Toward a choice architecture for regulators', Regulation \& Governance, https://doi.org/10.1111/rego.12329.

European Environment Agency (2001), Environmental signals 2001: European Agency regular indicator report [Publication]. Retrieved from: https://www.eea.europa.eu/publications/signals-2001.

Ewert, B. and K. Loer (2020), 'Advancing behavioural public policies: In pursuit of a more comprehensive concept', Policy \& Politics, https://doi.org/10.1332/030557320X15907721287475.

Ewert, B., K. Loer and E. Thomann (2020), 'Beyond nudge: Advancing the state-of-the-art of behavioural public policy and administration', Policy \& Politics, https://doi.org/10.1332/030557320X15987279194319.

Falco, P. and S. Zaccagni (2020), Promoting social distancing in a pandemic: Beyond the good intentions. https://doi.org/10.31219/osf.io/a2nys.

Favero, N. and M. J. Pedersen (2020), "How to encourage "Togetherness by Keeping Apart" amid COVID-19? The ineffectiveness of prosocial and empathy appeals', Journal of Behavioral Public Administration, 3(2): Article 2. https://doi.org/10.30636/jbpa.32.167.

Feitsma, J. and M. Whitehead (2019), 'Bounded interdisciplinarity: Critical interdisciplinary perspectives on context and evidence in behavioural public policies', Behavioural Public Policy, 1-27. https://doi. org/10.1017/bpp.2019.30.

Final Mile (2020), Pandemic playbook. Pandemic Playbook. Retrieved from: https://www.playbookforpandemic.com.

Galizzi, M. M. (2014), 'What is really behavioral in behavioral health policy? And does it work?', Applied Economic Perspectives and Policy, 36(1): 25-60.

George, B. (2020), 'Revisiting public management as a design science', Journal of Public Administration Research and Theory, 30(3): 524-6. https://doi.org/10.1093/jopart/muaa015.

Glueck, W. F. (1976), Business policy: Strategy formation and management action (2nd ed.). Chicago: McGraw-Hill.

Golemon, L. (2019), 'Medical overtesting and racial distrust', Kennedy Institute of Ethics Journal, 29(3): 273-303. https://doi.org/10.1353/ken.2019.0025.

Grand, J. L. (2020), 'Some challenges to the new paternalism', Behavioural Public Policy, 1-12. https://doi. org/10.1017/bpp.2020.12. 
Gujral, V., R. Palter, A. Sanghvi and B. Vickery (2020),'Commercial real estate must do more than merely adapt to coronavirus.', Retrieved from: https://www.mckinsey.com/industries/private-equity-and-principal-investors/our-insights/commercial-real-estate-must-do-more-than-merely-adapt- to-coronavirus.

Hallsworth, M., V. Snijders, H. Burd, J. Prestt, G. Judah, S. Huf and D. Halpern (2016), Simple ways to improve health outcomes. World Innovation Summit for Health. Doha, Qatar, 29-30 November 2016.

Hampton, K., L. Fernandez, C. Robertson and J. M. Bauer (2020), Broadband and student performance gaps (SSRN Scholarly Paper ID: 3614074). Social Science Research Network. https://doi.org/10.2139/ssrn. 3614074.

Hansen, P. G. (2018), 'What are we forgetting?', Behavioural Public Policy, 2(2): 190-7. https://doi.org/10. 1017/bpp.2018.13.

Hassmiller Lich, K., J. B. Urban, L. Frerichs and G. Dave (2017), 'Extending systems thinking in planning and evaluation using group concept mapping and system dynamics to tackle complex problems', Evaluation and Program Planning, 60: 254-64. https://doi.org/10.1016/j.evalprogplan.2016.10.008.

Haynes, P. (2018), 'Understanding the influence of values in complex systems-based approaches to public policy and management', Public Management Review, 20(7): 980-96. https://doi.org/10.1080/14719037. 2017.1364411.

Haynes, L., O. Service, B. Goldacre and D. Torgerson (2012), 'Test, learn, adapt: Developing public policy with randomised controlled trials', SSRN Electronic Journal, https://doi.org/10.2139/ssrn.2131581.

Henderson, B. D. (1989), The origin of strategy. Harvard Business Review, November-December 1989. Retrieved from: https://hbr.org/1989/11/the-origin-of-strategy.

Hermus, M., A. van Buuren and V. Bekkers (2020), 'Applying design in public administration: A literature review to explore the state of the art', Policy \& Politics, 48(1): 21-48. https://doi.org/10.1332/ $030557319 X 15579230420126$.

Ho, T.-H., C. Leong and C. Yeung (2020), 'Success at scale: Six suggestions from implementation and policy sciences', Behavioural Public Policy, 1-9. https://doi.org/10.1017/bpp.2020.20.

Holling, C. S. (2001), 'Understanding the complexity of economic, ecological, and social systems', Ecosystems, 4(5): 390-405. https://doi.org/10.1007/s10021-001-0101-5.

Hong, L. and S. E. Page (2004), 'Groups of diverse problem solvers can outperform groups of high-ability problem solvers', Proceedings of the National Academy of Sciences, 101(46): 16385-89. https://doi.org/10. 1073/pnas.0403723101.

Howlett, M. (2019), Designing public policies: Principles and instruments. London: Routledge.

Howlett, M. (2020), 'Challenges in applying design thinking to public policy: Dealing with the varieties of policy formulation and their vicissitudes', Policy \& Politics, 48(1): 49-65. https://doi.org/10.1332/ 030557319X15613699681219.

IJzerman, H., N. A. Lewis, A. K. Przybylski, N. Weinstein, L. DeBruine, S. J. Ritchie, S. Vazire, P. S. Forscher, R. D. Morey, J. D. Ivory and F. Anvari (2020), 'Use caution when applying behavioural science to policy', Nature Human Behaviour, 1-3. https://doi.org/10.1038/s41562-020-00990-w.

Irrational Labs (2020), Behavioral design guide. Retrieved from: https://irrationallabs.com/learn/.

Iwuoha, V. C. and E. T. Aniche (2020), 'Covid-19 lockdown and physical distancing policies are elitist: Towards an indigenous (Afro-centred) approach to containing the pandemic in sub-urban slums in Nigeria', Local Environment, 25(8): 631-40. https://doi.org/10.1080/13549839.2020.1801618.

Jilke, S., A. L. Olsen, W. Resh and S. Siddiki (2019), 'Microbrook, mesobrook', Perspectives on Public Management and Governance, 2(4): 245-53. https://doi.org/10.1093/ppmgov/gvz015.

Johnson, S. (2019), 'What works: When and why are nudges sticky, scaleable and transferable?', Journal of Behavioral Economics for Policy, 3(Special Issue): 19-21.

Johnson, T., C. Dawes, J. Fowler and O. Smirnov (2020), 'Slowing COVID-19 transmission as a social dilemma: Lessons for government officials from interdisciplinary research on cooperation', Journal of Behavioral Public Administration, 3(1): Article 1. https://doi.org/10.30636/jbpa.31.150.

Jones, C., D. W. Hine and A. D. G. Marks (2017), 'The future is now: reducing psychological distance to increase public engagement with climate change', Risk Analysis, 37(2): 331-41. https://doi.org/10.1111/ risa. 12601.

Kaplan, R. S., H. B. Leonard and A. Mikes (2020), 'The risks you can't foresee', Harvard Business Review, 98 (6): 40-6. 
Kelders, S. M., R. N. Kok, H. C. Ossebaard and J. E. V. Gemert-Pijnen (2012), 'Persuasive system design does matter: a systematic review of adherence to web-based interventions', Journal of Medical Internet Research, 14(6): e152. https://doi.org/10.2196/jmir.2104.

Kimbell, L. (2016), 'Design in the time of policy problems', Proceedings of DRS2016. Design + Research + Society - Future-Focused Thinking. Retrieved from: https:/ualresearchonline.arts.ac.uk/id/eprint/9542/ 1/DRS2016_Kimbell_final.pdf.

Kimbell, L. and J. Bailey (2017), 'Prototyping and the new spirit of policy-making', CoDesign, 13(3): 21426. https://doi.org/10.1080/15710882.2017.1355003.

Lafley, A. G. and R. L. Martin (2013), Playing to win: How strategy really works, Boston: Harvard Business Press.

Laurent-Simpson, A. and C. C. Lo (2019), 'Risk society online: Zika virus, social media and distrust in the Centers for Disease Control and Prevention', Sociology of Health \& Illness, 41(7), https:/doi.org/10.1111/ 1467-9566.12924.

Learned, E., R. Christensen, K. Andrews and W. Guth (1969), Business policy: Text and cases. Homewood, IL: Irwin.

Levinson, J. D. and K. Peng (2006), Valuing cultural differences in behavioral economics (SSRN Scholarly Paper ID 899688). Social Science Research Network. Retrieved from: https://papers.ssrn.com/ abstract $=899688$.

Levitt, S. D. and J. A. List (2007), 'Viewpoint: On the generalizability of lab behaviour to the field', Canadian Journal of Economics/Revue Canadienne d'économique, 40(2): 347-70. https://doi.org/10. 1111/j.1365-2966.2007.00412.x.

Lewandowsky, S., J. Cook, P. Schmid and D. I. Holford (2021), The COVID-19 Vaccine Communication Handbook. A practical guide for improving vaccine communication and fighting misinformation. SciBeh Project. Retrieved from: https://hackmd.io/@scibehC19vax/home.

Lunn, P. D., C. A. Belton, C. Lavin, F. P. McGowan, S. Timmons and D. A. Robertson (2020), 'Using behavioral science to help fight the Coronavirus', Journal of Behavioral Public Administration, 3(1), https://doi. org/10.30636/jbpa.31.147.

Manning, L., A. G. Dalton, A. Zeina, R. Vakox and F. Naru (2020), Behavioral science around the world volume ii: profiles of 17 International Organizations (p. 204) [EMBeD report]. World Bank Group.

Mantzari, E., G. J. Rubin and T. M. Marteau (2020), 'Is risk compensation threatening public health in the Covid-19 pandemic?', BMJ, 370, https://doi.org/10.1136/bmj.m2913.

Matias, N. and A. Leavitt (2020), COVID-19 International Academic Social Science Research Project Tracker. Retrieved from: https://docs.google.com/spreadsheets/d/1DuY8VLV2yG8TAOZbtyNtrhHERmzUjSaXpA 00_59z_XU/edit?ts=5e73b15d\#gid $=60477339$.

Maxmen, A. and J. Tollefson (2020), 'Two decades of pandemic war games failed to account for Donald Trump', Nature, 584(7819): 26-9. https://doi.org/10.1038/d41586-020-02277-6.

Mažar, N. (2019), Behavioral economics: Ethics and integrative thinking. Behavioral Science Solutions Ltd. Retrieved from: https://open.bu.edu/handle/2144/39951.

Meadows, D. (1999), Leverage points: Places to intervene in a system (p. 18). Hartland, VT: Sustainability Institute.

Mellers, B., E. Stone, T. Murray, A. Minster, N. Rohrbaugh, M. Bishop, E. Chen, J. Baker, Y. Hou, M. Horowitz, L. Ungar and P. Tetlock (2015), 'Identifying and cultivating superforecasters as a method of improving probabilistic predictions', Perspectives on Psychological Science, 10(3): 267-81. https://doi. org/10.1177/1745691615577794.

Meng, J., M. McLaughlin, K. Pariera and S. Murphy (2016), 'A comparison between Caucasians and African Americans in willingness to participate in cancer clinical trials: The roles of knowledge, distrust, information sources, and religiosity', Journal of Health Communication, 21(6): 669-77. https://doi.org/ 10.1080/10810730.2016.1153760.

Michie, S., M. Richardson, M. Johnston, C. Abraham, J. Francis, W. Hardeman, M. P. Eccles, J. Cane and C. E. Wood (2013), 'The behavior change technique taxonomy (v1) of 93 hierarchically clustered techniques: Building an international consensus for the reporting of behavior change interventions', Annals of Behavioral Medicine, 46(1): 81-95. https://doi.org/10.1007/s12160-013-9486-6.

Mills, S. (2020), 'Personalized nudging', Behavioural Public Policy, 1-10. https://doi.org/10.1017/bpp.2020.7. 
Mintrom, M. and J. Luetjens (2016), 'Design thinking in policymaking processes: Opportunities and challenges', Australian Journal of Public Administration, 75(3): 391-402. https://doi.org/10.1111/1467-8500. 12211.

Mintzberg, H. (1979), The structuring of organizations. Englewood Cliffs, NJ: Prentice-Hall.

Mintzberg, H. and A. McHugh (1985), 'Strategy formation in an adhocracy', Administrative Science Quarterly, 30(2): 160-97. https://doi.org/10.2307/2393104.

Missoni, E., B. Armocida and B. Formenti (2020), 'Face masks for all and all for face masks in the COVID-19 pandemic: Community level production to face the global shortage and shorten the epidemic', Disaster Medicine and Public Health Preparedness, 1-5. https://doi.org/10.1017/dmp.2020.207.

Nair, S. and M. Howlett (2016), 'From robustness to resilience: Avoiding policy traps in the long term', Sustainability Science, 11(6): 909-17. https://doi.org/10.1007/s11625-016-0387-z.

National Academies of Sciences, Engineering, and Medicine (2020), Framework for equitable allocation of COVID-19 vaccine. The National Academies Press. https://doi.org/10.17226/25917.

Nelson, M. J. and C. Witko (2020), 'Government reputational effects of COVID-19 public health actions: A job opportunity evaluation conjoint experiment', Journal of Behavioral Public Administration, 3(1): Article 1. https://doi.org/10.30636/jbpa.31.174.

Nicola, M., C. Sohrabi, G. Mathew, A. Kerwan, A. Al-Jabir, M. Griffin, M. Agha and R. Agha (2020), 'Health policy and leadership models during the COVID-19 pandemic: A review', International Journal of Surgery, 81: 122-9. https://doi.org/10.1016/j.ijsu.2020.07.026.

Nogueira, A., W. S. Ashton and C. Teixeira (2019), 'Expanding perceptions of the circular economy through design: Eight capitals as innovation lenses', Resources, Conservation and Recycling, 149: 56676. https://doi.org/10.1016/j.resconrec.2019.06.021.

Nordgren, L. F., J. van. der. Pligt and F. van. Harreveld (2007), 'Unpacking perceived control in risk perception: The mediating role of anticipated regret', Journal of Behavioral Decision Making, 20(5): 533-44. https://doi.org/10.1002/bdm.565.

Phillips, K. W. (2014), 'How diversity works', Scientific American, 311(4): 42-7. https://doi.org/10.1038/ scientificamerican1014-42.

Poteat, T., G. A. Millett, L. E. Nelson and C. Beyrer (2020), 'Understanding COVID-19 risks and vulnerabilities among black communities in America: The lethal force of syndemics', Annals of Epidemiology, 47: 1-3. https://doi.org/10.1016/j.annepidem.2020.05.004.

Read, C. (1920), Logic deductive and inductive (Revised edition). London: Simkin Marshall.

Reijula, S. and R. Hertwig (2020), 'Self-nudging and the citizen choice architect', Behavioural Public Policy, 1-31. https://doi.org/10.1017/bpp.2020.5.

Reijula, S., J. Kuorikoski, T. Ehrig, K. Katsikopoulos and S. Sunder (2018), 'Nudge, boost, or design? Limitations of behaviorally informed policy under social interaction', Journal of Behavioral Economics for Policy, 2(1): 99-105. https://doi.org/10.31235/osf.io/zh3qw.

Riley, W. T., W. J. Nilsen, T. A. Manolio, D. R. Masys and M. Lauer (2015), 'News from the NIH: Potential contributions of the behavioral and social sciences to the precision medicine initiative', Translational Behavioral Medicine, 5(3): 243-6. https://doi.org/10.1007/s13142-015-0320-5.

Rittel, H. W. J. and M. M. Webber (1973), 'Dilemmas in a general theory of planning', Policy Sciences, 4(2): 155-69. https://doi.org/10.1007/BF01405730.

Saltelli, A., G. Bammer, I. Bruno, E. Charters, M. D. Fiore, E. Didier, W. N. Espeland, J. Kay, S. L. Piano, D. Mayo, R. Pielke Jr, T. Portaluri, T. M. Porter, A. Puy, I. Rafols, J. R. Ravetz, E. Reinert, D. Sarewitz, P. B. Stark and P. Vineis (2020), 'Five ways to ensure that models serve society: A manifesto', Nature, 582 (7813): 482-4. https://doi.org/10.1038/d41586-020-01812-9.

Sanders, M., V. Snijders and M. Hallsworth (2018), 'Behavioural science and policy: Where are we now and where are we going?', Behavioural Public Policy, 2(2): 144-67. https://doi.org/10.1017/bpp.2018.17.

Sarlo, R., G. Pereira, M. Surica, D. Almeida, C. Araújo, O. Figueiredo, E. Rocha and E. Vargas (2016), 'Impact of introducing full-time in-house coordinators on referral and organ donation rates in Rio de Janeiro Public Hospitals: A Health Care Innovation Practice', Transplantation Proceedings, 48(7): 2396-8. https://doi.org/10.1016/j.transproceed.2015.11.044.

Schmidt, R (2020), 'Strange bedfellows: Design research and behavioral design', in Boess, S., Cheung, M. and Cain, R. (eds.), Synergy - DRS International Conference 2020, 11-14 August. https://doi.org/10. 21606/drs.2020.252. 
Schmidt, R. and K. Stenger (2021), 'Behavioral planning: Improving behavioral design with "roughly right" foresight', Strategic Design Research Journal, 14(1): 138-148. https://doi.org/10.4013/sdrj.2021.141.12.

Schoemaker, P. J. H. (1995), 'Scenario planning: A tool for strategic thinking', Sloan Management Review, 36 (2): $25-40$.

Shangraw, R. F. S. Jr and M. M. Crow (1998), 'Public administration as a design science', International Journal of Public Administration, 21(6-8): 1059-77. https://doi.org/10.1080/01900699808525334.

Sheeran, P. and T. L. Webb (2016), 'The intention-behavior gap', Social and Personality Psychology Compass, 10(9): 503-18. https://doi.org/10.1111/spc3.12265.

Shore, B. J., A. Y. Nasreddine and M. S. Kocher (2012), 'Overcoming the funding challenge: The cost of randomized controlled trials in the next decade', JBJS, 94(Supplement_1): 101-6. https://doi.org/10. 2106/JBJS.L.00193.

Siebert, H. (2001), Der Kobra-Effekt. Wie man Irrwege der Wirtschaftspolitik vermeidet (in German). Munich: Deutsche Verlags-Anstalt.

Smith, D. M., G. Loewenstein, A. Jankovic and P. A. Ubel (2009), 'Happily hopeless: Adaptation to a permanent, but not to a temporary, disability', Health Psychology, 28(6): 787-91. https://doi.org/10.1037/ a0016624.

Soman, D. and T. Hossain (2020), 'Successfully scaled solutions need not be homogenous', Behavioural Public Policy, 1-10. https://doi.org/10.1017/bpp.2020.24.

Spencer, N. (2018), 'Complexity as an opportunity and challenge for behavioural public policy', Behavioural Public Policy, 2(2): 227-34. https://doi.org/10.1017/bpp.2018.20.

Star, S. L. and J. R. Griesemer (1989), 'Institutional ecology, "translations" and boundary objects: Amateurs and professionals in Berkeley's museum of vertebrate zoology, 1907-39', Social Studies of Science, 19(3): 387-420.

Sunstein, C. R. (2018), 'Misconceptions about nudges', Journal of Behavioral Economics for Policy, 2(1): 61-97. https://doi.org/10.2139/ssrn.3033101.

Sunstein, C. R. (2020a), 'The meaning of masks', Journal of Behavioral Economics for Policy, 4(COVID-19 Special Issue): 5-8. https://doi.org/10.2139/ssrn.3571428.

Sunstein, C. R. (2020b), Behavioral science and public policy (1st ed.). Cambridge University Press. https:// doi.org/10.1017/9781108973144.

Supplee, L. H. and M. C. Kane (2020), 'The realities of scaling within evidence-based policy', Behavioural Public Policy, 1-13. https://doi.org/10.1017/bpp.2020.25.

Swanson, D. and S. Bhadwal (2009), Creating adaptive policies: A guide for policymaking in an uncertain world. London: IDRC.

Tanrivermiş, H. (2020), 'Possible impacts of COVID-19 outbreak on real estate sector and possible changes to adopt: A situation analysis and general assessment on Turkish perspective', Journal of Urban Management, 9(3): 263-9. https://doi.org/10.1016/j.jum.2020.08.005.

Thaler, R. (2016), 'Behavioral economics: Past, present, and future', American Economic Review, 106(7): 1577-600. https://doi.org/10.1257/aer.106.7.1577.

Thaler, R. (2017), 'Much Ado about nudging', Behavioral Public Policy Blog. Retrieved from: https:// bppblog.com/2017/06/02/much-ado-about-nudging/.

Thaler, R. and S. Benartzi (2004), 'Save more tomorrow ${ }^{\text {TM }}$ : Using behavioral economics to increase employee saving', Journal of Political Economy, 112(S1): S164-87. https://doi.org/10.1086/380085.

Thaler, R. and H. M. Shefrin (1981), 'An economic theory of self-control', Journal of Political Economy, 89 (2): 392-406. https://doi.org/10.1086/260971.

Thaler, R. and C. Sunstein (2008), Nudge: Improving decisions about health, wealth, and happiness. New Haven: Yale University Press.

Tidwell, J. (2020), Handwashing Behavior Change Research and COVID-19 [Guide]. Retrieved from: https:// docs.google.com/document/u/1/d/1pkO9kEgDqD07UP93zBZbZz5354rSYWVJy_mH_i7D7TM/edit?usp= embed_facebook.

Trischler, J., S. J. Pervan, S. J. Kelly and D. R. Scott (2018), 'The value of codesign: The effect of customer involvement in service design teams', Journal of Service Research, 21(1): 75-100. https://doi.org/10.1177/ 1094670517714060.

Tromp, N., P. Hekkert and P.-P. Verbeek (2011), 'Design for socially responsible behavior: A classification of Influence Based on Intended User Experience', Design Issues, 27(3): 3-19. https://doi.org/10.1162/ DESI_a_00087. 
UCRC Staff \& Wilson Water Group (2018), Colorado river system conservation pilot program in the Upper Colorado River Basin. The Upper Colorado River Commission. Retrieved from: http://www.ucrcommission.com/RepDoc/SCPPDocuments/2018_SCPP_FUBRD.pdf.

Utych, S. M. and L. Fowler (2020), 'Age-based messaging strategies for communication about COVID-19', Journal of Behavioral Public Administration, 3(1): Article 1. https://doi.org/10.30636/jbpa.31.151.

Uyterhoeven, H. E. R., R. W. Ackerman and J. W. Rosenblum (1977), Strategy and organization: Text and cases in general management. Homewood, IL: Irwin.

Van Bavel, R. and F. Dessart (2018), The case for qualitative methods in behavioural studies for EU policymaking. Joint Research Centre Science Hub. https://doi.org/10.2760/861402.

van Buuren, A., J. M. Lewis, B. Guy Peters and W. Voorberg (2020), 'Improving public policy and administration: Exploring the potential of design', Policy \& Politics, 48(1): 3-19. https://doi.org/10.1332/ $030557319 X 15579230420063$.

Vargas, E. D. and G. R. Sanchez (2020). American individualism is an obstacle to wider mask wearing in the US. Brookings. Retrieved from: https://www.brookings.edu/blog/up-front/2020/08/31/american-individualism-is-an-obstacle-to-wider-mask-wearing-in-the-us/.

Vincent-Lamarre, P., C. R. Sugimoto and V. Larivière (2020), Monitoring women's scholarly production during the COVID-19 pandemic [Shiny Dashboard]. Canada Research Chair on the Transformations of Scholarly Communication of Université de Montréal. Retrieved from: http://shiny.initiativesnumeriques.org/monitoring-scholarly-covid/.

Wilkinson, T. M. (2013), 'Nudging and manipulation', Political Studies, 61(2): 341-55. https://doi.org/10. 1111/j.1467-9248.2012.00974.x.

Wojda, T. R., S. P. Stawicki, K. P. Yandle, M. Bleil, J. Axelband, R. Wilde-Onia, P. G. Thomas, J. Cipolla, W. S. Hoff and J. Shultz (2017), 'Keys to successful organ procurement: An experience-based review of clinical practices at a high-performing health-care organization', International Journal of Critical Illness and Injury Science, 7(2): 91-100. https://doi.org/10.4103/IJCIIS.IJCIIS_30_17.

World Health Organization (2020), 'Water, sanitation, hygiene, and waste management for SARS-CoV-2, the virus that causes COVID-19: Interim guidance', World Health Organization. 29 July 2020. Retrieved from: https://apps.who.int/iris/handle/10665/333560.

Yan, Y., J. Bayham, E. P. Fenichel and A. Richter (2020), 'Do face masks create a false sense of security? A COVID-19 dilemma', MedRxiv, 2020.05.23.20111302. https://doi.org/10.1101/2020.05.23.20111302.

Yancy, C. W. (2020), 'COVID-19 and African Americans', JAMA, https://doi.org/10.1001/jama.2020.6548. Yildirmaz, A., M. Goldar and S. Klein (2020), Illuminating the shadow workforce: Insights into the gig workforce in business. London: ADP Research Institute.

Cite this article: Schmidt R, Stenger K (2021). Behavioral brittleness: the case for strategic behavioral public policy. Behavioural Public Policy 1-26. https://doi.org/10.1017/bpp.2021.16 